\title{
Preserving identity in capture-mark-recapture studies: increasing the accuracy of minimum number alive (MNA) estimates by incorporating inter-census trapping efficiency variation
}

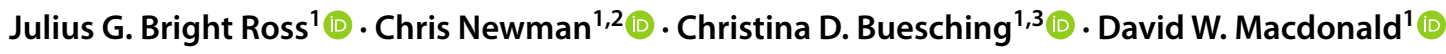

Received: 12 February 2021 / Accepted: 6 December 2021 / Published online: 22 February 2022

(c) The Author(s) 2022, corrected publication 2022

\begin{abstract}
Quantifying abundance is often key to understanding ecological and evolutionary processes in wild populations. Despite shortcomings in producing accurate abundance estimates, minimum number alive (MNA) remains a widely used tool, due to its intuitive computation, reliable performance as an abundance indicator, and linkage to individual life-histories. Here, we propose a novel "efficiency-modified" MNA (eMNA) metric, which aims to preserve MNA's favourable aspects while remedying its flaws, by incorporating (a) growth correlates to back-age individuals first captured as adults, and (b) estimates of undetected persistence beyond last capture based on time-varying capture efficiency. We evaluate eMNA through samplings of a simulated baseline population parameterised using data from a long-term demographic study of European badgers (Meles meles), under three different levels of capture efficiency (low; intermediate/"real" based on badger field data; high). We differentiate between eMNA's performance as an abundance estimator-how well it approximates true abundance (accuracy) — and as an abundance indicator — how tightly it correlates with population abundance and changes thereof (precision). eMNA abundance estimates were negatively biased at all capture efficiencies. However, this bias was negligible at intermediate-to-high capture efficiency, particularly once low-information terminal sampling years (the first year and final three years of simulated studies) were removed. Excluding these years, eMNA under-estimated abundance by only 3.5 badgers (1.5\% of population) at intermediate (real) capture efficiencies, and performed as a precise abundance indicator, with half the standard deviation of Cormack-Jolly-Seber probabilistic estimates and proving robust to inter-sampling variation in capture efficiency. Using undetected persistence probabilities to parameterise survival regression, we recreated baseline age-based survival relationships, albeit with some negative bias for under-represented ages. We offer considerations on the continued limitations of using eMNA for abundance estimates, minimum study duration for reliability, the metric's benefits when individual identity is required, and potential for further improvement.
\end{abstract}

Keywords Badgers $\cdot$ Calendar of catches $\cdot$ Capture-mark-recapture $\cdot$ Enumeration $\cdot$ Minimum number alive $\cdot$ Trappability

Handling editors: Stephen C.Y. Chan and Leszek Karczmarski.

This article is a contribution to the special issue on "Individual Identification and Photographic Techniques in Mammalian Ecological and Behavioural Research - Part 1: Methods and Concepts" - Editors: Leszek Karczmarski, Stephen C.Y. Chan, Daniel I. Rubenstein, Scott Y.S. Chui and Elissa Z. Cameron.

Julius G. Bright Ross

jbrightross@gmail.com

1 Wildlife Conservation Research Unit, Department of Zoology, The Recanati-Kaplan Centre, University of Oxford, Oxford, UK

\section{Introduction}

Long-term individual-based demographic studies are fundamental to ecology (Clutton-Brock and Sheldon 2010). The life-history and population contexts of an individual's birth, reproduction, and death shape the relationships between traits and fitness (Starrfelt and Kokko 2012; Sæther and

2 Cook's Lake Farming Forestry and Wildlife Inc (Ecological Consultancy), Queens County, NS, Canada

3 Department of Biology, Irving K. Barber Faculty of Sciences, The University of British Columbia, Okanagan, Kelowna, BC, Canada 
Engen 2015; Wright et al. 2019; Bright Ross et al. 2021), and thus ultimately whether an individual passes on its genes. The contextual information provided by linking individual life-history schedules with population dynamics underlies our understanding of much of ecology and evolution, from life-history theory (Stearns 1992) to density dependence (Coulson et al. 2001) and the existence of diverse fitness strategies within populations (Réale et al. 2010; Wright et al. 2019).

Minimum number alive (MNA), occasionally also termed minimum number known alive, calendar of catches, or simply enumeration, has been used as an individuallinked abundance indicator for decades (Krebs 1966; Macdonald and Newman 2002; Smith and Nichols 2003; Johnson et al. 2016, inter alia). MNA, like many other capture-mark-recapture (CMR) metrics, does not require actual marking, so long as individuals are consistently distinguishable (Ellison and Swanson 2016). This enables MNA, as an intuitively constructed metric, to easily incorporate various stacked forms of identification (Palomares et al. 2005), ranging from DNA fingerprinting (Meijer et al. 2008) and camera trapping (Lazenby et al. 2014) to opportunistic tourism photography (Marnewick et al. 2014). We note, however, that although "minimum number alive" has been used to describe a measure of abundance based on a single coalescence of data (representing one sampling occasion, even if over several months, Morley and van Aarde 2007; van den Hoven and Reilly 2012), here we define MNA strictly as the use of data from multiple sampling occasions to inform the presence of individuals not captured during intervening occasions.

Although clearly negatively biased (it is, after all, a "minimum"), MNA often correlates strongly with true abundance (Slade and Blair 2000; Pryde et al. 2005; Graipel et al. 2014; Johnson et al. 2016), particularly at higher degrees of population closure, survey frequency, and capture efficiency (the proportion of extant individuals captured or recaptured in a given capture session, Ruscoe et al. 2001; Pacheco et al. 2013). Therefore, while probabilistic approaches (ranging from simple Lincoln-Petersen estimators to multi-state CMR models, Pollock 2000; Lindberg 2012; Laake et al. 2013) may provide more accurate abundance estimators (accurate prediction of abundance), MNA can out-perform certain probabilistic metrics as an abundance indicator (precise correlation to changes in abundance, Davis et al. 2003), particularly when these approaches are hindered by obstructing terrain (as in transect distance sampling or double-observer abundance estimators) and/or cryptic animal behaviour (Corlatti et al. 2015, 2017), or under conditions that violate the assumption of equal catchability (Tuyttens 2000). Such an indicator can provide crucial information for ecological inquiry, such as abundance trends in different successional stages (Howe and Davlantes 2017) or in threatened populations (Pryde et al. 2005), comparative measures of abundance within a population over time (Bright Ross et al. 2020), or inter-specific (Fritts et al. 2017) and inter-population (Smith and Nichols 2003; Holloway et al. 2012) comparisons of abundance drivers. In the case of MNA, the indicator is also directly linked to individual life-history records, making it easy to test associations between population- and individual-scale processes (Bright Ross et al. 2020, 2021).

Nevertheless, MNA's utility as an abundance indicator belies significant shortcomings when it is used strictly to estimate abundance. As already mentioned, MNA is a negatively biased estimator (Bryja et al. 2001; Ramey et al. 2008; Mullican, 2014); this bias is exacerbated under low capture efficiency (Hilborn et al. 1976; Tuyttens 2000). Downstream metrics suffer as a result: MNA yields positively biased trappability (Byrne and Do Linh San 2016), and survival estimates based on MNA alone (implying immediate death after last capture, which is almost universally a poor assumption in an uncontrolled population) can lead to improper selection of covariates (Viallefont et al. 1999). When governments use MNA-based metrics for species management interventions that require accurate estimates and not simply indicators, such as planning and evaluating pest control (Ramey et al. 2008; Lazenby et al. 2014; Johnson et al. 2016) or informing species conservation plans (Biggins et al. 2006), these shortcomings become dangerous. Improvement to the MNA method's estimation ability would, therefore, improve the robustness of its use for such purposes while preserving the metric's intuitive computation and links to individual animals.

In this study, we make use of demographic data from a long-term demographic study on European badgers (Meles meles). Badgers are fossorial, nocturnal animals, presenting ecologists with considerable challenges when attempting to enumerate them for study (Noonan et al. 2015a). Their trappability varies substantially between sites, seasons, and years (Byrne et al. 2012; Noonan et al. 2015b), but accurately estimating their abundance is often crucial, as they act as a reservoir of bovine tuberculosis (Mycobacterium bovis) in Britain and Ireland (Vicente et al. 2007). Governmental interventions-whether by culling (Donnelly et al. 2006; Byrne et al. 2014), vaccination campaigns (Carter et al. 2012), or a combination of the two (Abdou et al. 2016) —all require reliable appraisals of capture efficiency and abundance. Beyond these epidemiological applications, badgers have been used to study the effects of population density on individual condition (Macdonald et al. 2002; Bright Ross et al. 2021), development (Sugianto et al. 2019; van Lieshout et al. 2021), life-history strategies (Bright Ross et al. 2020), mating physiology (Sugianto et al. 2021), energetics (Barbour et al. 2019), parasitology (Albery et al. 2020), and social organisation (Johnson et al. 2001), among other topics, and in turn to study the effects of climate (Macdonald 
and Newman 2002; Macdonald et al. 2010) and habitat change (da Silva et al. 1993; Delahay et al. 2006) on abundance. These diverse ecological applications illustrate the importance of choosing an abundance metric that appropriately characterises the population being studied, holding as it does ramifications for all downstream findings.

Using simulations parameterised with 32 years of badger demographic data, we propose and evaluate the indication and estimation performance of a novel efficiency-modified minimum number alive (eMNA) metric, which improves on standard MNA by (a) back-aging individuals first captured as adults, based on growth correlates, and (b) incorporating estimates of undetected survival beyond last capture, based on time-varying capture efficiency. We mimic a range of demographic trapping studies by sampling the same baseline simulated population at three capture efficiencies: (1) the relatively high capture efficiency of the badger study underlying the simulations (average $73.8 \%$ annually, termed "intermediate" and "real" in this manuscript, Bright Ross et al. 2020); (2) the lower capture efficiencies better representative of many studies of small mammals (taken from Parmenter et al. 2003); and (3) particularly high capture efficiencies, to evaluate whether eMNA might overestimate true abundance in near-optimal trapping regimes. We then test whether the method's preserved individual linkages permit analysis of mortality predictors from estimated persistence probabilities. Finally, we use further simulations to identify how study length might affect eMNA's reliability. This paper aims not to characterise every possible population to which this method could be applied, but rather to characterise a range of conditions suitable enough for the interested practitioner to judge its applicability to their own circumstances.

\section{Methods}

To streamline further use of the method, we conducted all simulations, calculations, and analyses in R statistical software ( $\mathrm{R}$ Core Team, 2019); where relevant, we have indicated specific packages below. All code and data are available at https://doi.org/10.7910/DVN/4D4XPT, annotated to facilitate adaptation, and we encourage alternative parameterisation of simulations as a precursor to using the method in a different study system.

\section{Demographic data collection}

We collected data for parameterising simulations from a badger population in Wytham Woods, a $4.24 \mathrm{~km}^{2}$ mixed woodland in southern England $\left(51^{\circ} 46^{\prime} \mathrm{N}, 1^{\circ} 20^{\prime} \mathrm{W}\right.$; for more information, see Savill 2011). The population is situated on a hill surrounded by the River Thames on three sides and the A34 motorway on the fourth, making the population more or less closed to migration (immigration/emigration rate $=3 \%$ : Macdonald and Newman 2002). From 1987 to 2019 , we trapped every active communal burrow systemtermed a "sett" (consisting of 1-10 holes, with 5.5 individuals cohabitating in the average sett, though occupancy ranges from 1 to 28) - in the study area using string-trigger traps for two or (most commonly) three nights, three-four times per year, at regular seasonal intervals (for breakdown of seasonal dates, see Bright Ross et al. 2021). We transferred badgers to holding cages between 7:00 and 9:00 a.m., transported them to a central field station, and sedated them with $0.2 \mathrm{~mL}$ ketamine hydrochloride/kg body weight by intramuscular injection (Sun et al. 2015). On first capture (typically as a cub or yearling), we gave each badger a unique numerical inguinal tattoo. On each capture, we estimated degree of molar tooth wear as a scaled value from 1 to 5 , which has been shown to be useful for estimating age retrospectively in cases when individuals were first caught as adults (Hancox 1988; Bright Ross et al. 2020).

All badger captures were licensed under the Badger Act (1992) (currently Natural England license 2019-2020-4417) and all handling procedures carried out under Animals (Scientific Procedures) Act (1986) license (currently PPL 30/3379).

\section{Generating baseline population}

We used real badger data (henceforth, "real" data, subscript $r$ ) to generate a 30-year baseline time series of individual life-histories (henceforth, "baseline" data, subscript $b$ ) that could be iteratively sampled to simulate a range of capture efficiency scenarios. Hereafter, scalars will be indicated with unbolded italics (both uppercase and lowercase), vectors will be indicated with bolded lowercase italics, and matrices with bolded uppercase italics. Subscripts will indicate first to which dataset a given value refers (real, baseline, or "captured" in simulations, subscript $c$ ), and second to the corresponding numerical time-step (if relevant) - where subscript $t$ refers to a generic time-step.

We generated a baseline population of individuals in the first time-step $\left(N_{b 1}\right)$, for which an age-distribution vector $\boldsymbol{n}_{\boldsymbol{b} \boldsymbol{1}}$ was initiated with the average number of badgers of each age in the 32 years of real data (Eq. 1).

$$
n_{b 1}=\operatorname{mean}\left(\boldsymbol{n}_{r 1}, n_{r 2} \ldots n_{r 32}\right) \text {. }
$$

Although a small minority (4.5\%) of individuals in the studied population survive beyond age 10 (with the oldest known-age individual reaching age 14, Macdonald et al. 2015), we capped our baseline population at age 10. This was done for two reasons: first, to minimise the number of estimated parameters in Cormack-Jolly-Seber (CJS) models-by far the most computationally intensive step of our 
analysis; second, to simplify the iterative population sampling procedure, where excluding those $4.5 \%$ of old badgers will not make the baseline population substantially different from the real badger population from which it is simulated. We adopt a post-reproductive census approach, because badgers are synchronous annual breeders that give birth to cubs in February (Woodroffe and Macdonald 1995) and a majority of badger mortality occurs during the winter (Macdonald et al. 2010; Bright Ross et al. 2021), while the majority of our CMR capture regime occurs during spring-autumn (Bright Ross et al. 2021). Therefore, we simulated 29 subsequent $\boldsymbol{n}_{b t}$ vectors in a two-step process, for a total of 30 "years" of baseline data (different study lengths tested in "Assessing robustness to study length variation" below). First, we calculated survival to time $t$ by vector-multiplying the previous age distribution by age- and sex-specific survival probabilities $\left(s_{r}\right.$, see Eq. 2$)$. We then summed together the number of surviving females in all age classes and multiplied the total by the mean maternity rate $m_{r}=\operatorname{mean}\left(m_{r 1} \ldots\right.$ $m_{r 32}$ ) (Eq. 3) to produce the number of cubs in time $t$. The cubs produced took the first index of the new $\boldsymbol{n}_{\boldsymbol{b t}}$ vector, while the surviving badgers of other age classes moved down a position in the vector (gained a year of age); the sum of this vector constituted the size of the baseline population at time $t\left(N_{b t}\right.$, Eq. 4). Although badgers display strong age dependence of maternity (and paternity) rates (Bright Ross et al. 2020; Sugianto et al. 2020), for simplicity's sake here we assume homogeneous maternity rates at all ages. So, for time $t$ in 2-30:

$$
\text { Survived }_{b(t-1)}=\sum_{a=1}^{10}\left(\boldsymbol{n}_{\boldsymbol{b}(t-1)} * \boldsymbol{s}_{\boldsymbol{r}}\right)
$$

$$
\begin{gathered}
\text { Cubs produced }_{b t}=\text { females survived }_{b(t-1)} * m_{r}, \\
N_{b t}=\text { Survived }_{b(t-1)}+\text { Cubs produced }_{b t} .
\end{gathered}
$$

We estimated the constituent values of $s_{r}$ using generalised additive models ( $m g c v$ package, Wood 2011) to fit sex-specific age splines to individual survival (binomial, $1=$ survived to time $t+1 ; 0=$ never detected past time $t$ ). Although this method is imperfect in deducing true survival relationships, as it assumes death for individuals that were not detected (where these may persist, undetected, as we permit when estimating survival relationships later in our workflow), this is not problematic in this step of the analysis, as it simply provides a baseline relationship to generate the population.

Given this series of $\boldsymbol{n}_{\boldsymbol{b t}}$ vectors, we created a matrix of life-histories $\left(\boldsymbol{L} \boldsymbol{H}_{\boldsymbol{b}}\right)$, with a row for each individual that had ever been alive in the population, transacted by 30 columns, one for each year of the baseline time series (Fig. 1). In $\boldsymbol{L H}_{\boldsymbol{b}}$, $1 \mathrm{~s}$ represent years in which a badger was alive and 0s, years in which it was not (whether for having died or not yet being born); thus, each row's sum equals the total number of years that individual was alive (in the simulated study) and each column's sum equals that year's $N_{b t}$ value. We matched these individual life-histories with context matrices (time-varying)

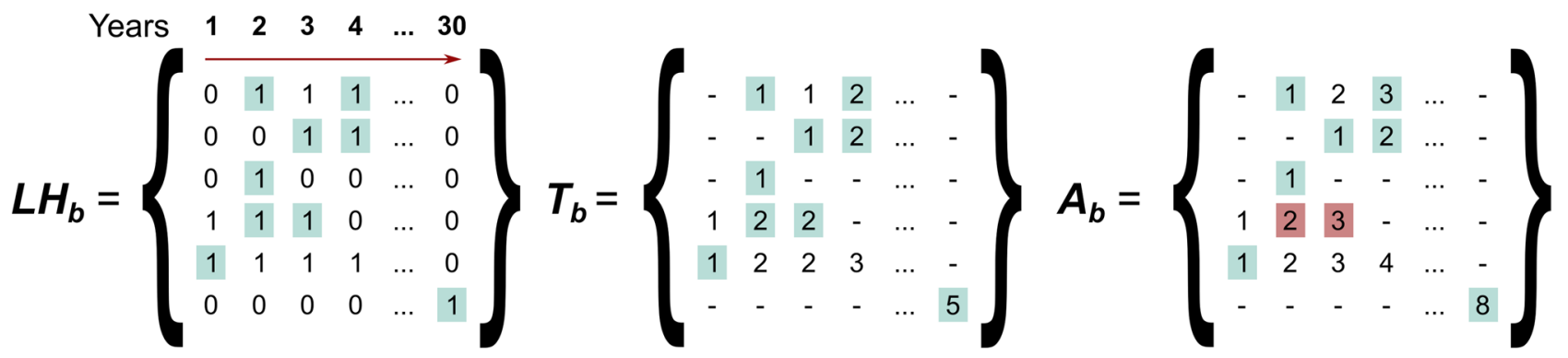

1000 iterations

$$
\boldsymbol{L}_{\boldsymbol{c}}=\left(\begin{array}{llllll}
0 & 1 & 0 & 1 & \ldots & 0 \\
0 & 0 & 1 & 1 & \ldots & 0 \\
0 & 1 & 0 & 0 & \ldots & 0 \\
0 & 1 & 1 & 0 & \ldots & 0 \\
1 & 0 & 0 & 0 & \ldots & 0 \\
0 & 0 & 0 & 0 & \ldots & 1
\end{array}\right\} \boldsymbol{T}_{\boldsymbol{c}}=\left\{\begin{array}{cccccc}
- & 1 & 2 & \ldots & - \\
- & - & 1 & 2 & \ldots & - \\
- & 1 & - & - & \ldots & - \\
-2 & 2 & - & \ldots & - \\
1 & - & - & - & \ldots & - \\
- & - & - & - & \ldots & 5
\end{array}\right\} \boldsymbol{A}_{\boldsymbol{c}}=\left(\begin{array}{cccccc}
1 & 2 & 3 & \ldots & - \\
- & - & 1 & 2 & \ldots & - \\
- & 1 & - & - & \ldots & - \\
2 & 3 & 4 & - & \ldots & - \\
1 & - & - & - & \ldots & - \\
- & - & - & - & \ldots & 8
\end{array}\right\}
$$

Fig. 1 Life-history and context matrices. Top row shows baseline matrices (those data to be sampled); bottom row shows the outcomes of one sampling iteration, with boxed numbers indicating sampled badgers in a given year. Red boxes in $\boldsymbol{A}_{\boldsymbol{b}}$ illustrate an individual first caught at age 2; that individual's tooth wear at first capture (index $\{4,2\}$ in $\boldsymbol{T}_{\boldsymbol{c}}$ ) can then be used to deduce its age at the time and backage the individual's life-history (red arrow) for use in subsequent steps of the enumeration process 
and vectors (constant individual characteristics) representing individual information such as age $\left(\boldsymbol{A}_{\boldsymbol{b}}\right.$, known from $\left.\boldsymbol{n}_{b t}\right)$, sex, and tooth wear $\left(\boldsymbol{T}_{\boldsymbol{b}}\right)$. These matrices and vectors (a) enable easy iterative sampling of the population and (b) help pre-format the data for interfacing with MARK (White and Burnham 1999) or other related demographic analysis software such as the marked package (Laake et al. 2013, used for this manuscript's CJS estimates), which uses MARK syntax to compute models in R. $\boldsymbol{T}_{\boldsymbol{b}}$ values for any position $\{i, j\}$ were assigned by sampling the real tooth wear data for all badgers of an equal age to $\boldsymbol{A}_{\boldsymbol{b}\{i, j\}}$.

\section{Computing abundance estimates with variable trapping efficiency}

We sampled the baseline population 1000 times under three different time-varying capture efficiency $\left(c e_{b t}\right)$ regimes: "low" efficiency (each $c e_{b t}$ sampled from a uniform distribution from 45 to $55 \%$, characteristic of many small mammal trapping regimes, Parmenter et al. 2003); an intermediate "real" efficiency (each $c e_{b t}$ sampled from a multi-modal distribution built to resemble that of real badger trapping efficiencies $c e_{r t}$, which averaged 74\%); and "high" efficiency ( $c e_{b t}$ sampled from a uniform distribution from 85 to $95 \%$ ). For each $c e_{b t}$ value, we "captured" that percentage of the "1" values in the corresponding year column of $\boldsymbol{L H}_{\boldsymbol{b}}$ (and its context matrices), simulating the process of imperfect detection in a "captured" life-history matrix, $\boldsymbol{L H}_{\boldsymbol{c}}$ (Fig. 1).

We computed four different estimates of population abundance: three variants of minimum number alive (together, "enumeration" estimators) and one using a Cormack-Jolly-Seber (CJS) estimate of detection probability. $M N A_{c t}$ represents simply adding "captured" $\left(C_{c t}\right)$ individuals and those known from previous and subsequent captures to be alive but uncaptured in time $t$ ("alive, uncaptured", $A U_{c t}$ ):

$$
M N A_{c t}=C_{c t}+A U_{c t}
$$

This number can be improved using context matrices to estimate ages at first capture for those individuals first caught as adults. In our case, we regressed real tooth wear against real age (using non-linear least squares in the stats package, see Bright Ross et al. 2020) to produce a relationship from which we could predict the age of unknown-age individuals based on their first sampled tooth wear (see Fig. 1 for example). For these individuals, life-history records could be back-projected to relevant years $\left(B P_{c t}\right)$ to produce agemodified MNA $\left(a M N A_{c t}\right)$ :

$$
a M N A_{c t}=M N A_{c t}+B P_{c t} .
$$

Estimated time-varying capture efficiency itself $\left(c e_{c t}\right.$, estimated as the proportion of known-alive individuals captured in time $t$ ) can also be used to estimate the probability that an individual $i$ last captured at time $j-x$ remained undetected but alive in the population at time $j$; this probability is the product of the probability of non-detection $\left(1-c e_{c t}\right)$ in each intervening year (we artificially lowered this probability to 0 past age 10 , for reasons discussed above):

$$
\begin{aligned}
c e_{c t} & =\frac{C_{c t}}{A U_{c t}+C_{c t}}, \\
P\left(\text { alive }_{i, j}\right) & =\prod_{t=(j-x)+1}^{j}\left(1-c e_{c t}\right) .
\end{aligned}
$$

By summing these persistence probabilities for undetected-but-alive individuals in a given year, we calculated efficiency-modified MNA values $\left(e M N A_{c t}\right)$ :

$$
e M N A_{c t}=a M N A_{c t}+\sum_{i=1}^{n} P\left(\text { alive }_{i, t}\right)
$$

Finally, we also estimated abundance by implementing CJS models with the marked package (Laake et al. 2013) to provide a benchmark for the three stepwise varieties of MNA estimates. CJS models estimate two determinant parameters of detection: $\varphi$, the apparent survival (death and emigration) from time $t-1$ to $t$ (in these simulations, apparent survival $=$ survival as no emigration was modelled) and $p$, the probability of detection at time $t$ given survival from $t-1$; both $\varphi$ and $p$ can be estimated as a function of time-varying and/or constant covariates. In each iterated sampling, we estimated $p$ separately for each year $\left(p_{c t}\right.$, an alternative estimate of $c e_{c t}$ ), and $\varphi$ as a function of age, sex, and their interaction. Therefore, population abundance estimates $\left(C J S_{c t}\right)$ using this method could be derived by dividing the captured individuals in time $t$ by the detection probability:

$$
C J S_{c t}=\frac{C_{c t}}{p_{c t}} .
$$

We could not compute this value for the first year of each iteration, as CJS models require a time $t-1$ for parameter estimation.

\section{Assessing robustness to study length variation}

We investigated how more or fewer data affected eMNA's precision and accuracy. To do so, we re-sampled $\boldsymbol{L H}_{\boldsymbol{b}} 100$ times for each study length between 1 and 30 timesteps ("years") and at each of the three levels of capture efficiency. These 9000 "studies" of varying lengths and capture efficiencies permitted the deduction of (a) how many years of data would be sufficient to reach peak abundance estimation performance and (b) whether the method suffers from information bias-i.e. if the greater information closer to the 
temporal centre of the study results in statistically weaker estimates at the study's beginning and end.

\section{Estimating survival relationships using efficiency-modified persistence probabilities}

Given a series of known life-histories, individual survival probability can be expressed as a binomial linear regression, where case 1 represents known survival and case 0 represents known death. Imperfect capture efficiency (timevarying or otherwise), however, violates the assumption that an undetected individual at time $t$ has died; therefore, the probability of undetected persistence must be considered. One possible solution to this issue is to use the probability an individual truly died after its final capture at time $t$ (probability of "dead, uncaptured", $D U_{c t}$ ) to weight observations from different individuals in the survival regression:

$$
\text { Weight }_{i}=D U_{c t}=1-A U_{c t} \text {. }
$$

We used these individual weightings to regress individual survival as a function of an individual's sex, age, and their interaction, producing a within-iteration estimate of these survival relationships $\left(\boldsymbol{s}_{c}\right)$ to compare with the mortality schedules used to generate the population.

\section{Results}

\section{Performance of different approaches as abundance estimators and indicators}

At all time-steps along the 30-year simulation, enumeration estimators were negatively biased with regard to the baseline simulated abundance (Figs. 2a-c, 3); CJS probabilistic
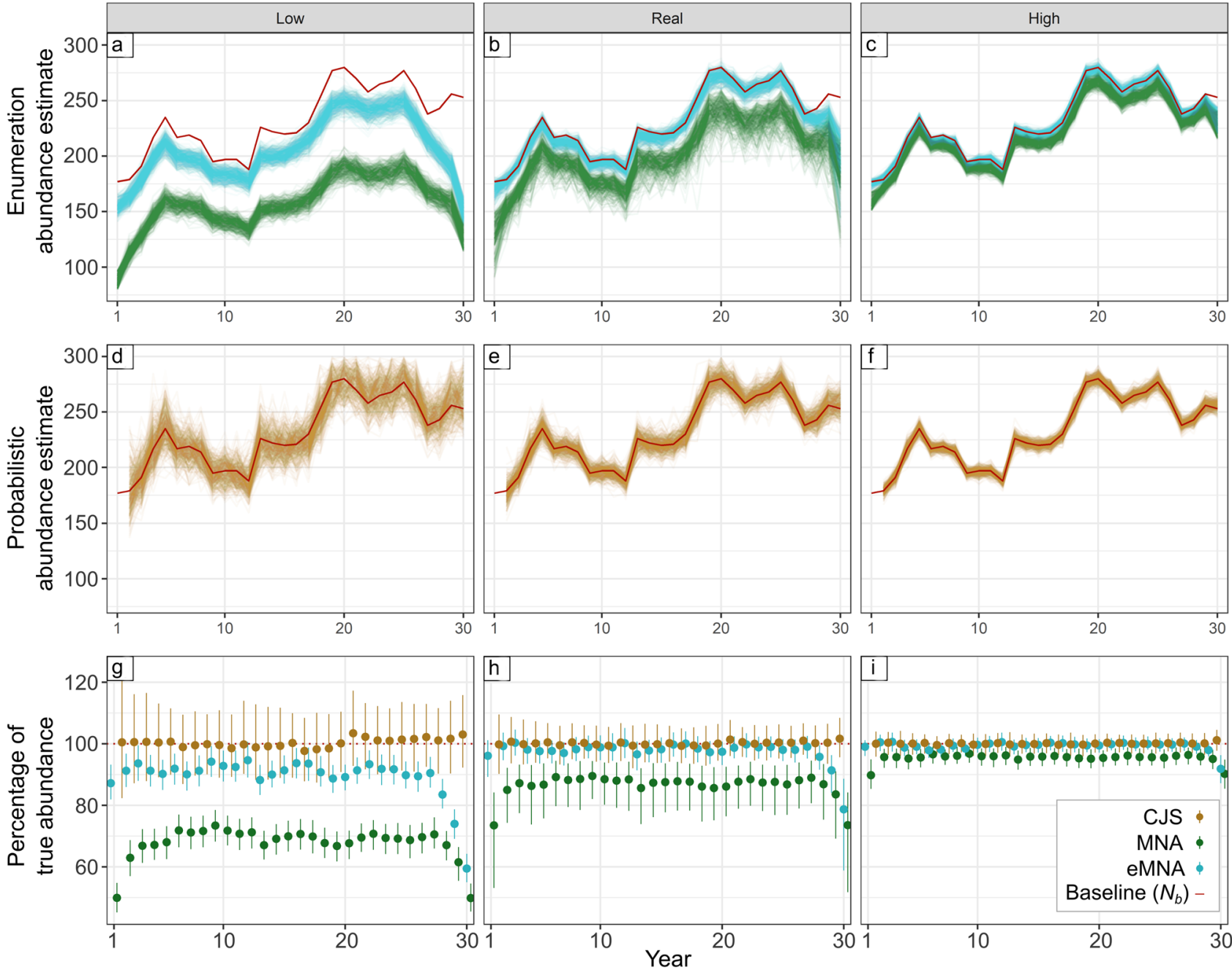

Fig. 2 Yearly simulation results. For plots a-f, each line represents a single iteration $(n=1000)$ of 30 years of sampling at low $(45-55 \%)$, real (intermediate, based on badger rates), and high (85-95\%) capture efficiency for either enumeration (MNA and eMNA) or probabilistic (CJS) methods. Panes $\mathbf{g}-\mathbf{i}$ show mean iteration estimate and $95 \%$ quantile, as percentage of the baseline simulation's abundance $\left(N_{b}\right)$ 


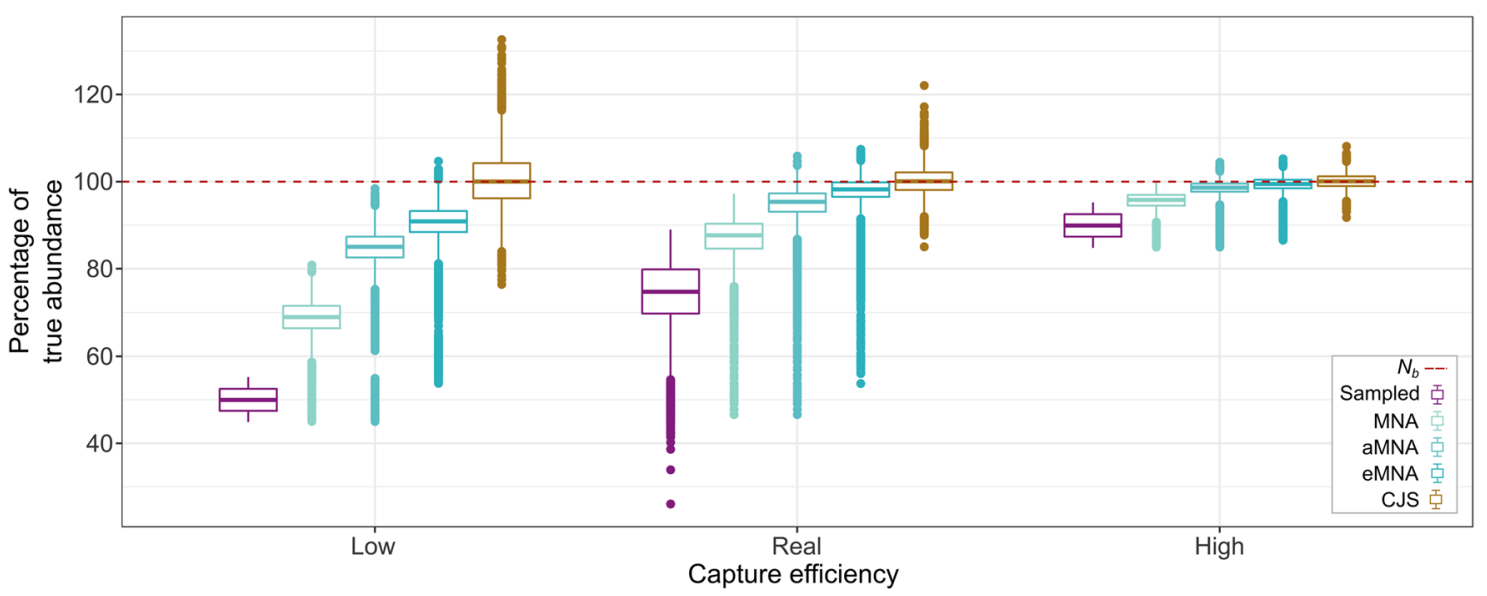

Fig. 3 Abundance estimation by method. Boxplots display annual deviations from the baseline sampled population (with the exception of the first year of each iteration) for 1000 samplings under either low, real, or high capture efficiency

estimation was not (Fig. 2d-f). Underestimation of baseline abundance by MNA, aMNA, and eMNA was strongest at lower average capture efficiencies, and negative bias was relatively low for eMNA at intermediate and high capture efficiencies (Figs. 2a-c, 3). Moreover, this negative bias was relatively consistent, with the exception of the first sampling occasion (in this case, year) and the final two (high capture efficiency) or three (low or real capture efficiency) occasions (Figs. 2g-i, 4). After excluding these low-reliability years, eMNA provided a particularly informative abundance indicator, proving more robust to inter-annual fluctuations in time-varying capture efficiency than CJS estimates, with lower spread of abundance estimates over the 1000 sampling iterations-particularly at low capture efficiencies and those modelled after real badger data (Fig. 2d, e). Following particularly rapid population dynamics shifts (see year 13 in Fig. 2 and repeated patterns in Fig. 4), enumeration approaches exhibited an additional minor lagged negative bias.

Each stepwise improvement to MNA reduced the negative bias of abundance estimates, with MNA, aMNA and eMNA estimates deviating from the baseline abundance by $-13.20 \%(\mathrm{SD}=5.11 \%),-5.60 \%(\mathrm{SD}=5.30 \%)$, and $-2.50 \%(\mathrm{SD}=4.63 \%)$, respectively, under intermediate capture efficiencies modelled after real badger data (Fig. 3; numbers calculated without first year to enable like-forlike comparison with CJS, which was accurate on average to within $1 \%$ under all capture efficiencies). In the case of eMNA, this translates to an underestimation of 6.1 badgers
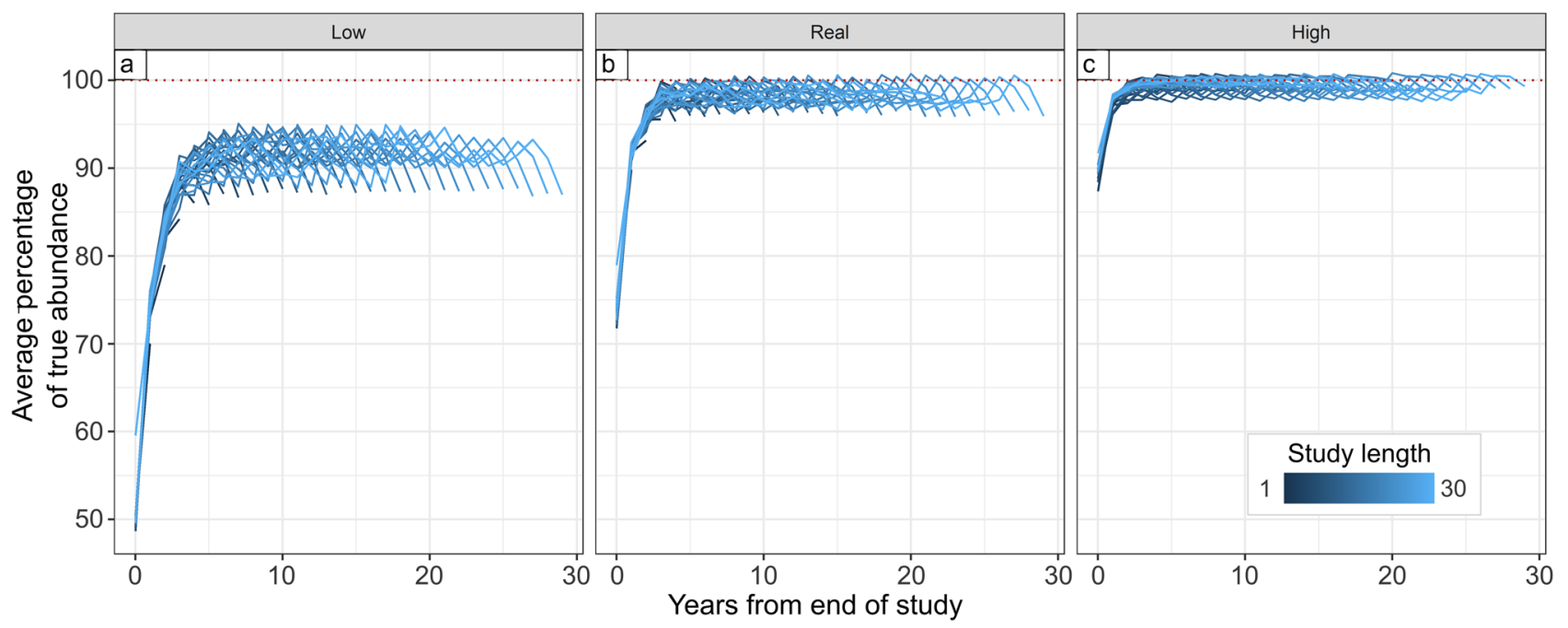

Fig. 4 Average annual eMNA abundance estimation, indexed by year from end of study. Each line displays the average annual abundance estimation for 100 iterations of a given study length, ranging from 1 to 30 years long. Lines are arranged so that the last year of a study is on the left, to illustrate the similar underestimation rates in these terminal years, irrespective of study length 
in an average year at intermediate capture efficienciescompared with an overestimate of 0.4 badgers by CJS. This underestimation was not evenly distributed across the years of simulated studies. While the first year of a simulated study (the right terminal point of lines in Fig. 4) somewhat underperformed the middle years of the study, the majority of underestimation occurred in the last 2-4 years (depending on capture efficiency but irrespective of overall study length, see Fig. 4), as these were the only years where back-aging could not retroactively improve undersamplings. Beyond these years, eMNA gained substantial reliability as both an estimator and indicator: for instance, underestimation improved to $-1.48 \%(\mathrm{SD}=2.25 \%)$ under intermediate capture efficiencies, equivalent to 3.5 badgers, after excluding the last three and first year of a given simulation. Moreover, after excluding these terminal sampling years, while eMNA was substantially more biased at low average capture efficiencies than CJS $(-8.58 \%$ vs. $+0.15 \%$, respectively), eMNA was far less susceptible to fluctuations from inter-annual capture efficiency variation than CJS was, with the standard deviation of eMNA estimates being equivalent to only $3.07 \%$, half of CJS' standard deviation of $6.18 \%$ under the same conditions (see the inter-annual "sawing" tendencies of CJS estimates in Fig. 2d).

The reliability of eMNA abundance estimates at all capture efficiencies depended on the duration of a study (Fig. 5). At high capture efficiencies, eMNA only had an annual average bias of $-3.70 \%$ even for a 4-year study; while at intermediate capture efficiencies, at least 5 years of data were required for average annual bias to improve over $-10 \%$; at low capture efficiencies, eMNA never reached $90 \%$ of $N_{b}$ on average, but surpassed $80 \%$ (a $-20 \%$ average annual bias) after 7 years of data sampling. Figure 5 includes all years of a simulated study in the average and standard deviation, giving the impression of steadily improving estimation and indication as study length increases; in fact, eMNA performance stabilises substantially in the middle years of a study, as seen in Fig. 4 (see Fig. A1 for a version of Fig. 5 excluding the first year and last 3 years).

\section{Estimates of age-survival relationships from persistence probabilities}

In nearly all sampling iterations under capture efficiencies modelled after real badger data, regressions weighted by probability of persistence beyond last detection recreated the baseline relationship between age and sex-specific survival (Fig. 6b, e). The validity of this regression method, however, was dependent on capture efficiency. First, a negative survival probability bias was evident at younger ages, particularly at low capture efficiency-for instance, survival rates of age 0 badgers (cubs) were under-estimated by $11.9 \%$

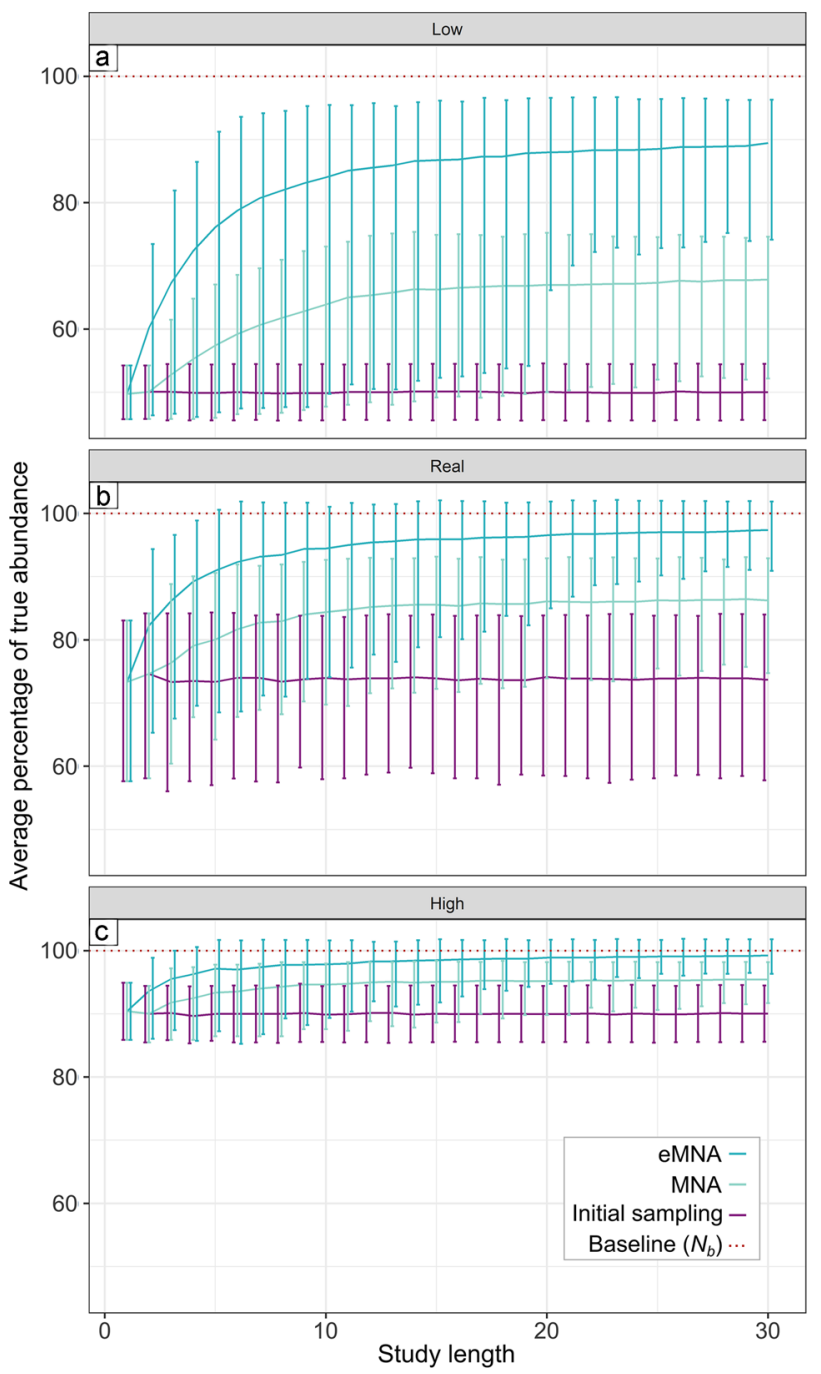

Fig. 5 Effect of study length on MNA and eMNA performance. Lines show the average badgers sampled and average annual MNA and eMNA estimates across 100 simulations at different study lengths; error bars indicate the $95 \%$ quantiles

$(\mathrm{SD}=2.3 \%)$ in males and $9.6 \%(\mathrm{SD}=2.1 \%)$ in females (Fig. 6a, d), though this decreased to just 3.8\% ( $\mathrm{SD}=1.1 \%$ ) and $2.6 \%$ ( $\mathrm{SD}=1.1 \%)$, respectively, at capture efficiencies modelled after real data (Fig. 6b, e). Second, survival probability at older ages was slightly overestimated for high capture efficiencies-for instance, survival rates of age 9 badgers were overestimated by $4.4 \%(\mathrm{SD}=3.1 \%)$ in males and $2.4 \%(\mathrm{SD}=2.4 \%)$ in females (Fig. $6 \mathrm{c}, \mathrm{f})$.

\section{Discussion}

All forms of enumeration exhibited negative bias as abundance estimators (that is, in their ability to reproduce the underlying baseline population size), particularly at low 

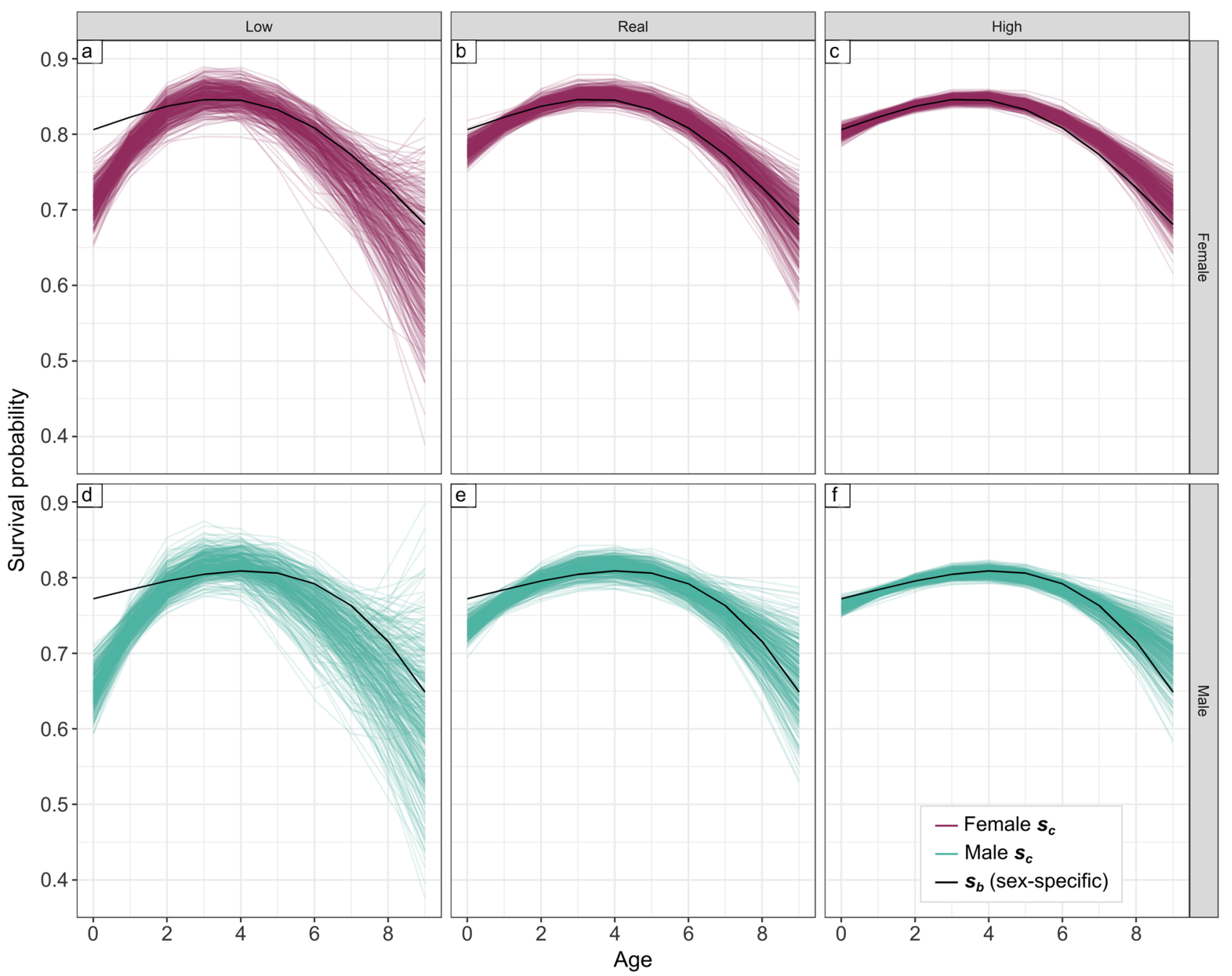

Fig. 6 Relationship between survival and age inferred from persistence probabilities. Coloured lines (purple $=$ female, blue $=$ male) show estimated relationships from 1000 samplings under low, real, and high capture efficiencies; black lines show baseline relationship

capture efficiencies. However, under intermediate (based on real badger data) or high capture efficiencies, this negative bias was minimal in eMNA estimates, particularly after removal of terminal low-information years (the first year and last 3 years of a given study). Moreover, after these terminal years were removed, enumeration methods (and particularly eMNA) represented abundance indices (that is, metrics correlated with the underlying baseline population) that were more robust to inter-annual variation in capture efficiency than probabilistic CJS outputs, even under low capture efficiency. The only instances in which trimmed eMNA underperformed CJS outputs as an abundance indicator were directly after abrupt changes in abundance. Due to the low accuracy of eMNA estimates in the first year and last 2-3 years of a study, eMNA required at least 5 years of data at intermediate capture efficiencies to provide a reliable abundance estimator or indicator. Finally, although estimating age-survival relationships through regression weighted with capture efficiency-modified persistence probabilities was hindered by the effects of imperfect capture efficiency on age representation in these data, most sampling iterations successfully approximated the baseline survival relationships, especially at intermediate capture efficiencies.

It has long been established that MNA's performance as an abundance estimator is sensitive to trapping efficiency (Hilborn et al. 1976). Nevertheless, its intuitive computation and usefulness as an abundance indicator have ensured its continued use for ecological studies (Smith and Nichols 2003; Holloway et al. 2012; Fritts et al. 2017; Howe and Davlantes 2017), conservation assessments (Sei and Porter 2003; Meijer et al. 2008), and governmental species management interventions (Ramey et al. 2008; Lazenby et al. 2014; Johnson et al. 2016). It is particularly useful for small or endangered populations 
(Sei and Porter 2003; Palomares et al. 2005; Meijer et al. 2008), as it provides a hard "floor" instead of the often wide ranges associated with probabilistic estimates at low abundance (Meijer et al. 2008), and because its direct links to individual life-histories facilitates the computation of life tables and associated population parameters (Krebs 1985). The improvements we make here on MNA preserve this individual focus: rather than projecting a number of individuals with unknown features, it enables quantification of persistence probabilities for individuals with known features, benefitting from the careful design of most long-term demographic studies and the implicit additional information compiled in the resulting datasets. Using age-varying covariates to improve age estimation of individuals at first capture (Bird et al. 2019) and accounting for variable detection probabilities (White 2005) have both improved population parameter estimation in other methods. Here, by incorporating both factors in our eMNA formulation, we developed MNA's capacity to act not only as a valid density indicator, but also as a suitable density estimator under intermediate-to-high capture efficiencies, while preserving the features that distinguish enumeration from probabilistic approaches (although eMNA is, strictly, a partially probabilistic approach itself).

Nevertheless, our results illustrate several of eMNA's persisting shortcomings under certain study conditions. First, as documented elsewhere for MNA (Pocock et al. 2004), eMNA's negative bias on our badger dataset was exacerbated during the first sampling and last two to three samplings of the population, making it of limited use as either an estimator or indicator unless in the context of long-term datasets (Clutton-Brock and Sheldon 2010). Based on the results of our analysis, we do not recommend using estimates from these terminal samplings. Therefore, while Fig. A1 illustrates that, after excluding these years, eMNA is a robust indicator at any capture efficiency and a relatively reliable estimator at intermediate-to-high capture efficiencies, the sample size of estimates valid for analysis is $n-4$, where $n$ is the number of years in the study.

Second, although eMNA handles inter-annual capture efficiency variation relatively well with animals such as badgers with lives that (on average) span multiple sampling recapture iterations (Fig. 2), consistently lower capture efficiency does introduce substantially higher negative bias (Fig. 2a). This risks low comparability if either interpopulation habitat differences (Smith and Nichols 2003) or habitat changes (Howe and Davlantes 2017) result in substantially different capture efficiencies. Similarly, if detectability and/or baseline prevalence is particularly low, as occurs for example in cetacean and other marine animal surveys (Poncelet et al. 2010; Rinaldi et al. 2021), eMNA's negative bias is likely to be even greater. In these cases, methods such as CJS and closed-subpopulation models, the latter of which was developed using badger data (Tuyttens 2000), provide much more accurate abundance estimates (Byrne et al. 2012). Alternative approaches also exist that can explicitly estimate migration in open populations (see Link and Barker 2010); if migration is more substantial - and time-varying - than in the population studied here, enumeration methods should be tested under those specific conditions before use. Similarly, if the study species in question has a substantially shorter maximum age than badgers, the reduced frequency of back-aging may diminish enumeration's utility; in this eventuality, we recommend re-parameterising simulations.

Finally, estimation of survival rates and determinants thereof is risky when using approaches, such as MNA, that assume perfect detection of death (Viallefont et al. 1999). In addition to under-estimating survival rates, enumeration approaches ignore unmarked individuals (Graipel et al. 2014), which can lead to issues such as those seen in our estimates, which consistently under-estimated juvenile survival (Fig. 6). MNA methods have notwithstanding been used to calculate survival, particularly when populations are small (e.g. Sei and Porter 2003; Palomares et al. 2005). We caution that in such cases, researchers and conservation practitioners should carefully consider how certain sub-groups may be over- or under-represented in their capture data. For instance, based on Fig. 6, survival rates are likely to be increasingly overestimated at higher capture efficiencies for older ages, such as ages 11-14 in badgers (excluded from these simulations).

Despite its limitations, enumeration remains a powerful tool for wildlife ecologists. While model selection with probabilistic approaches can determine the drivers of individual survival and detection (Laake et al. 2013), eMNA directly connects individual persistence to population trends (Bright Ross et al. 2020, 2021) and provides a robust abundance indicator for long-term studies. If eMNA is strengthened further by considering differential capture efficiency (and probability of persistence) as a function of prevailing conditions (Noonan et al. 2015b), individual state markers (Noonan et al. 2014), and population subgroups (Bryja et al. 2001) - all of which can substantially affect recapture probability-enumeration approaches can continue to serve as a useful tool in wildlife studies, particularly integrated into ensemble approaches that make use of additional data not considered in these simulations. Individual heterogeneity in particular presents one of the greatest challenges to studying wild populations (Davis et al. 2003), with individuals becoming trap-happy or trapshy as a result of any number of determinants (Byrne et al. 2012). Incorporating the underlying variance in individual trap responses should, therefore, be an explicit objective of future developments in similar metrics, lest this noise obscure ecological signals of import. Ultimately, however, 
it is this individual heterogeneity that forms the basis for many ecological processes (Hamel et al. 2018). Therefore, forming a detailed accounting of it as part of the process of enumerating the population's abundance is crucial to developing our understanding of the "portfolio" of individuals that constitute a population's first line of defence against external stressors (Schindler et al. 2015; Beever et al. 2017).

\section{Appendix 1}

See Fig. A1

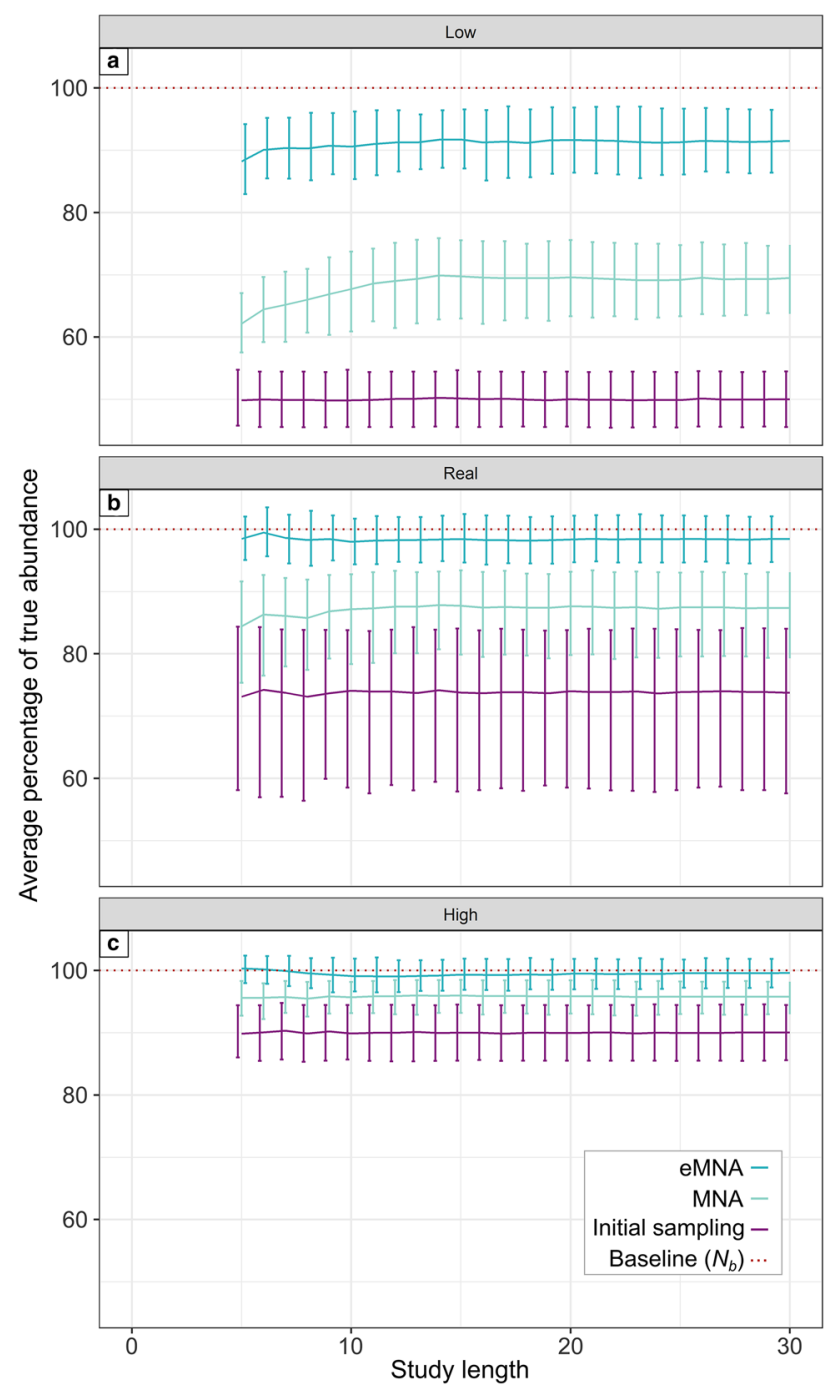

Fig. A1 Effect of study length on eMNA performance after trimming terminal years. Lines show the average badgers sampled and average annual MNA and eMNA estimates across 100 simulations at different study lengths; error bars indicate the $95 \%$ quantiles. In all cases, the first year and final three years of the study were excluded from the sample (see Fig. 4 and analysis of abundance estimation suitability in main text for reasoning)
Supplementary Information The online version contains supplementary material available at https://doi.org/10.1007/s42991-021-00210-6.

Author contributions Conceptualization: JGBR and CN; Data collection: CN, CDB, and DWM; Coding and analysis: JGBR; Writing: all authors.

Funding JGBR was supported by a Marshall Scholarship through the Marshall Aid Commemoration Commission and $\mathrm{CN}$ was funded by the H.N. Southern Fellowship in Ecology.

Availability of data, material, and code The full data and code used for this study are available online at the Wytham Woods Badger Project Harvard Dataverse: https://doi.org/10.7910/DVN/4D4XPT.

\section{Declarations}

Conflict of interest The authors have no relevant financial or non-financial interests to disclose.

Ethics approval All badger captures were licensed under the Badger Act (1992) (most recently Natural England license 2019-2020-4417) and all handling procedures carried out under Animals (Scientific Procedures) Act (1986) license (most recently PPL 30/3379).

Open Access This article is licensed under a Creative Commons Attribution 4.0 International License, which permits use, sharing, adaptation, distribution and reproduction in any medium or format, as long as you give appropriate credit to the original author(s) and the source, provide a link to the Creative Commons licence, and indicate if changes were made. The images or other third party material in this article are included in the article's Creative Commons licence, unless indicated otherwise in a credit line to the material. If material is not included in the article's Creative Commons licence and your intended use is not permitted by statutory regulation or exceeds the permitted use, you will need to obtain permission directly from the copyright holder. To view a copy of this licence, visit http://creativecommons.org/licenses/by/4.0/.

\section{References}

Abdou M, Frankena K, O'Keeffe J, Byrne AW (2016) Effect of culling and vaccination on bovine tuberculosis infection in a European badger (Meles meles) population by spatial simulation modelling. Prev Vet Med 125:19-30. https://doi.org/10.1016/j.prevetmed. 2015.12.012

Albery GF, Newman C, Bright Ross JG, Macdonald DW, Bansal S, Buesching CD (2020) Negative density-dependent parasitism in a group-living carnivore. Proc R Soc B Biol Sci 287:20202655. https://doi.org/10.1098/rspb.2020.2655

Barbour K, McClune DW, Delahay RJ, Speakman JR, McGowan NE, Kostka B, Montgomery WI, Marks NJ, Scantlebury DM (2019) No energetic cost of tuberculosis infection in European badgers (Meles meles). J Anim Ecol 88:1973-1985. https://doi.org/10. 1111/1365-2656.13092

Beever EA, Hall LE, Varner J, Loosen AE, Dunham JB, Gahl MK, Smith FA, Lawler JJ (2017) Behavioral flexibility as a mechanism for coping with climate change. Front Ecol Environ 15:299-308. https://doi.org/10.1002/fee.1502

Biggins DE, Godbey JL, Matchett MR, Hanebury T, Livieri TM, Marinari PE (2006) Monitoring black-footed ferrets during reestablishment of free-ranging populations: discussion of alternative 
methods and recommended minimum standards. In: Roelle JE, Miller BJ, Godbey JL, Biggins DE (eds) Recovery of the blackfooted ferret: progress and continuing challenges. US Geological Survey, Fort Collins, pp 155-174

Bird T, Lyon J, Wotherspoon S, Todd C, Tonkin Z, McCarthy M (2019) Combining capture-recapture data and known ages allows estimation of age-dependent survival rates. Ecol Evol 9:90-99. https://doi.org/10.1002/ece3.4633

Bright Ross JG, Newman C, Buesching CD, Macdonald DW (2020) What lies beneath? Population dynamics conceal pace-of-life and sex ratio variation, with implications for resilience to environmental change. Glob Chang Biol 26:3307-3324. https://doi. org/10.1111/gcb.15106

Bright Ross JG, Newman C, Buesching CD, Connolly E, Nakagawa S, Macdonald DW (2021) A fat chance of survival: body condition provides life-history dependent buffering of environmental change in a wild mammal population. Clim Chang Ecol 2:100022. https://doi.org/10.1016/j.ecochg.2021.100022

Bryja J, Tkadlec E, Nesvadbová J, Gaisler J, Zejda J (2001) Comparison of enumeration and Jolly-Seber estimation of population size in the common vole Microtus arvalis. Acta Theriol (warsz) 46:279-285. https://doi.org/10.1007/BF03192434

Byrne AW, Do Linh San E (2016) A cautionary note on the use of minimum number alive-derived trappability metrics in wildlife programmes, as exemplified by the case of the European badger (Meles meles). Wildl Biol Pract 12:51-57. https://doi.org/10. 2461/wbp.2016.eb.5

Byrne AW, O'Keeffe J, Green S, Sleeman DP, Corner LAL, Gormley E, Murphy D, Martin SW, Davenport J (2012) Population estimation and trappability of the European badger (Meles meles): implications for tuberculosis management. PLoS One 7:e50807. https://doi.org/10.1371/journal.pone.0050807

Byrne AW, White PW, McGrath G, O'Keeffe J, Martin SW (2014) Risk of tuberculosis cattle herd breakdowns in Ireland: effects of badger culling effort, density and historic largescale interventions. Vet Res 45:109. https://doi.org/10.1186/ s13567-014-0109-4

Carter SP, Chambers MA, Rushton SP, Shirley MDF, Schuchert P, Pietravalle S, Murray A, Rogers F, Gettinby G, Smith GC, Delahay RJ, Hewison RG, McDonald RA (2012) BCG vaccination reduces risk of tuberculosis infection in vaccinated badgers and unvaccinated badger cubs. PLoS One 7:e49833. https://doi.org/ 10.1371/journal.pone.0049833

Clutton-Brock T, Sheldon BC (2010) Individuals and populations: the role of long-term, individual-based studies of animals in ecology and evolutionary biology. Trends Ecol Evol 25:562-573. https:// doi.org/10.1016/j.tree.2010.08.002

Corlatti L, Fattorini L, Nelli L (2015) The use of block counts, markresight and distance sampling to estimate population size of a mountain-dwelling ungulate. Popul Ecol 57:409-419. https://doi. org/10.1007/s10144-015-0481-6

Corlatti L, Nelli L, Bertolini M, Zibordi F, Pedrotti L (2017) A comparison of four methods to estimate population size of Alpine marmot (Marmota marmota). Hystrix 28:61-67. https://doi.org/ 10.4404/hystrix-28.1-11698

Coulson T, Catchpole EA, Albon SD, Morgan BJT, Pemberton JM, Clutton-Brock TH, Crawley MJ, Grenfell BT (2001) Age, sex, density, winter weather, and population crashes in Soay sheep. Science (80-) 292:1528-1531. https://doi.org/10.1136/bmj.39050. 672639.80

da Silva J, Woodroffe R, Macdonald DW (1993) Habitat, food availability and group territoriality in the European badger, Meles meles. Oecologia 95:558-564. https://doi.org/10.1007/BF00317441

Davis SA, Akison LK, Farroway LN, Singleton GR, Leslie KE (2003) Abundance estimators and truth: accounting for individual heterogeneity in wild house mice. J Wildl Manage 67:634-645. https://doi.org/10.2307/3802720

Delahay RJ, Carter SP, Forrester GJ, Mitchell A, Cheeseman CL (2006) Habitat correlates of group size, bodyweight and reproductive performance in a high-density Eurasian badger (Meles meles) population. J Zool 270:437-447. https://doi.org/10.1111/j.14697998.2006.00165.x

Donnelly CA, Woodroffe R, Cox DR, Bourne FJ, Cheeseman CL, Clifton-Hadley RS, Wei G, Gettinby G, Gilks P, Jenkins H, Johnston WT, Le Fevre AM, McInerney JP, Morrison WI (2006) Positive and negative effects of widespread badger culling on tuberculosis in cattle. Nature 439:843-846. https://doi.org/10.1038/ nature 04454

Ellison SA, Swanson BJ (2016) Individual identification of raccoons (Procyon lotor) using track plate foot printing. Am Midl Nat 176:306-312. https://doi.org/10.1674/0003-0031-176.2.306

Fritts SR, Moorman CE, Grodsky SM, Hazel DW, Homyack JA, Farrell CB, Castleberry SB, Evans EH, Greene DU (2017) Rodent response to harvesting woody biomass for bioenergy production. J Wildl Manage 81:1170-1178. https://doi.org/10.1002/jwmg. 21301

Graipel ME, Hernández MIM, Salvador C (2014) Evaluation of abundance indexes in open population studies: a comparison in populations of small mammals in southern Brazil. Braz J Biol 74:553-559. https://doi.org/10.1590/bjb.2014.0077

Hamel S, Gaillard J-M, Yoccoz NG (2018) Introduction to: Individual heterogeneity - the causes and consequences of a fundamental biological process. Oikos 127:643-647. https://doi.org/10.1111/ oik.05222

Hancox M (1988) Field age determination in the European badger. Rev d'Ecologie (Terre Vie) 43:399-404. http://hdl.handle.net/ $2042 / 55336$

Hilborn R, Redfield JA, Krebs CJ (1976) On the reliability of enumeration for mark and recapture census of voles. Can J Zool 54:1019 1024. https://doi.org/10.1139/z76-114

Holloway GL, Smith WP, Halpern CB, Gitzen RA, Maguire CC, West SD (2012) Influence of forest structure and experimental greentree retention on northern flying squirrel (Glaucomys sabrinus) abundance. For Ecol Manage 285:187-194. https://doi.org/10. 1016/j.foreco.2012.08.025

Howe HF, Davlantes J (2017) Waxing and waning of a cotton rat (Sigmodon toltecus) monoculture in early tropical restoration. Trop Conserv Sci 10:1-11. https://doi.org/10.1177/1940082917704772

Johnson DDP, Macdonald DW, Newman C, Morecroft MD (2001) Group size versus territory size in group-living badgers: a largesample field test of the Resource Dispersion Hypothesis. Oikos 95:265-274. https://doi.org/10.1034/j.1600-0706.2001.950208.x

Johnson SR, Berentsen AR, Ellis C, Davis A, Vercauteren KC (2016) Estimates of small Indian mongoose densities: implications for rabies management. J Wildl Manage 80:37-47. https://doi.org/ 10.1002/jwmg.998

Krebs CJ (1966) Demographic changes in fluctuating populations of Microtus californicus. Ecol Monogr 36:239-273. https://doi.org/ $10.2307 / 1942418$

Krebs CJ (1985) Ecology: the experimental analysis of distribution and abundance, 3rd edn. Harper \& Row, Publishers, Inc, New York

Laake JL, Johnson DS, Conn PB (2013) Marked: an R package for maximum likelihood and Markov Chain Monte Carlo analysis of capture-recapture data. Methods Ecol Evol 4:885-890. https://doi. org/10.1111/2041-210X.12065

Lazenby BT, Mooney NJ, Dickman CR (2014) Effects of low-level culling of feral cats in open populations: a case study from the forests of southern Tasmania. Wildl Res 41:407-420. https://doi. org/10.1071/WR14030 
Lindberg MS (2012) A review of designs for capture-mark-recapture studies in discrete time. J Ornithol 152:S355-S370. https://doi. org/10.1007/s10336-010-0533-9

Link WA, Barker RJ (2010) Open population models. In: Bayesian inference with ecological applications. Academic Press, Boston, pp 239-270. https://doi.org/10.1016/B978-0-12-374854-6. 00014-4

Macdonald DW, Newman C (2002) Population dynamics of badgers (Meles meles) in Oxfordshire, U.K.: numbers, density and cohort life histories, and a possible role of climate change in population growth. J Zool 256:121-138. https://doi.org/10.1017/S095283690 2000158

Macdonald DW, Newman C, Stewart PD, Domingo-Roura X, Johnson PJ (2002) Density-dependent regulation of body mass and condition in badgers (Meles meles) from Wytham Woods. Ecology 83:2056-2061. https://doi.org/10.1890/0012-9658(2002) 083[2056:DDROBM]2.0.CO;2

Macdonald DW, Newman C, Buesching CD, Nouvellet P (2010) Are badgers "under the weather"? Direct and indirect impacts of climate variation on European badger (Meles meles) population dynamics. Glob Chang Biol 16:2913-2922. https://doi.org/10. 1111/j.1365-2486.2010.02208.x

Macdonald DW, Newman C, Buesching CD (2015) Badgers in the rural landscape-conservation paragon or farmland pariah? Lessons from the Wytham Badger Project. In: Macdonald DW, Feber RE (eds) Wildlife conservation on farmland. Oxford University Press, Oxford, pp 65-96

Marnewick K, Ferreira SM, Grange S, Watermeyer J, Maputla N, Davies-Mostert HT (2014) Evaluating the status of and African wild dogs Lycaon pictus and cheetahs Acinonyx jubatus through tourist-based photographic surveys in the Kruger National Park. PLoS One 9:e86265. https://doi.org/10.1371/journal.pone.00862 65

Meijer T, Norén K, Hellström P, Dalén L, Angerbjörn A (2008) Estimating population parameters in a threatened arctic fox population using molecular tracking and traditional field methods. Anim Conserv 11:330-338. https://doi.org/10.1111/j.1469-1795.2008. 00188.x

Morley RC, van Aarde RJ (2007) Estimating abundance for a savanna elephant population using mark-resight methods: a case study for the Tembe Elephant Park, South Africa. J Zool 271:418-427. https://doi.org/10.1111/j.1469-7998.2006.00225.x

Mullican TR (2014) Population estimates and habitat associations of the Bear Lodge meadow jumping mouse in the Black Hills of South Dakota. In: Proceedings of the South Dakota Academy of Science. pp 89-99

Noonan MJ, Markham A, Newman C, Trigoni N, Buesching CD, Ellwood SA, Macdonald DW (2014) Climate and the individual: Inter-annual variation in the autumnal activity of the European badger (Meles meles). PLoS One 9:e83156. https://doi.org/10. 1371/journal.pone.0083156

Noonan MJ, Markham A, Newman C, Trigoni N, Buesching CD, Ellwood SA, MacDonald DW (2015a) A new magneto-inductive tracking technique to uncover subterranean activity: What do animals do underground? Methods Ecol Evol 6:510-520. https:// doi.org/10.1111/2041-210X.12348

Noonan MJ, Rahman MA, Newman C, Buesching CD, Macdonald DW (2015b) Avoiding verisimilitude when modelling ecological responses to climate change: the influence of weather conditions on trapping efficiency in European badgers (Meles meles). Glob Chang Biol 21:3575-3585. https://doi.org/10.1111/gcb.12942

Pacheco M, Kajin M, Gentile R, Zangrandi PL, Vieira MV, Cerqueira $\mathrm{R}$ (2013) A comparison of abundance estimators for small mammal populations. Zoologia 30:182-190. https://doi.org/10.1590/ S1984-46702013000200008
Palomares F, Revilla E, Calzada J, Fernández N, Delibes M (2005) Reproduction and pre-dispersal survival of Iberian lynx in a subpopulation of the Doñana National Park. Biol Conserv 122:53-59. https://doi.org/10.1016/j.biocon.2004.06.020

Parmenter RR, Yates TL, Anderson DR, Burnham KP, Dunnum JL, Franklin AB, Friggens MT, Lubow BC, Miller M, Olson GS, Parmenter CA, Pollard J, Rexstad E, Shenk TM, Stanley TR, White GC (2003) Small-mammal density estimation: a field comparison of grid-based vs. web-based density estimators. Ecol Monogr 73:1-26. https://doi.org/10.1890/0012-9615(2003)073[0001: SMDEAF]2.0.CO;2

Pocock MJO, Frantz AC, Cowan DP, White PCL, Searle JB (2004) Tapering bias inherent in minimum number alive (MNA) population indices. J Mammal 85:959-962. https://doi.org/10.1644/ BPR-023

Pollock KH (2000) Capture-recapture models. J Am Stat Assoc 95:293-296. https://doi.org/10.2307/2669550

Poncelet É, Barbraud C, Guinet C (2010) Population dynamics of killer whales (Orcinus orca) in the Crozet Archipelago, southern Indian Ocean: a mark-recapture study from 1977 to 2002. J Cetacean Res Manag 11:41-48

Pryde MA, O’Donnell CFJ, Barker RJ (2005) Factors influencing survival and long-term population viability of New Zealand longtailed bats (Chalinolobus tuberculatus): implications for conservation. Biol Conserv 126:175-185. https://doi.org/10.1016/j.biocon. 2005.05.006

R Core Team (2019) R: A language and environment for statistical computing. https://www.r-project.org/

Ramey PC, Blackwell BF, Gates RJ, Slemons RD (2008) Oral rabies vaccination of a northern Ohio raccoon population: relevance of population density and prebait serology. J Wildl Dis 44:553-568. https://doi.org/10.7589/0090-3558-44.3.553

Réale D, Garant D, Humphries MM, Bergeron P, Careau V, Montiglio P-O (2010) Personality and the emergence of the pace-of-life syndrome concept at the population level. Philos Trans R Soc B Biol Sci 365:4051-4063. https://doi.org/10.1098/rstb.2010.0208

Rinaldi C, Rinaldi R, Laine J, Barbraud C (2021) Population dynamics of sperm whales (Physeter macrocephalus) in Guadeloupe, French Caribbean: a mark-recapture study from 2001 to 2013. Mar Mammal Sci 37:1391-1405. https://doi.org/10.1111/mms.12837

Ruscoe WA, Goldsmith R, Choquenot D (2001) A comparison of population estimates and abundance indices for house mice inhabiting beech forests in New Zealand. Wildl Res 28:173-178. https://doi. org/10.1071/WR00035

Sæther B-E, Engen S (2015) The concept of fitness in fluctuating environments. Trends Ecol Evol 30:273-281. https://doi.org/10. 1016/j.tree.2015.03.007

Savill PS (2011) Wytham Woods: Oxford's ecological laboratory. Oxford University Press, Oxford

Schindler DE, Armstrong JB, Reed TE (2015) The portfolio concept in ecology and evolution. Front Ecol Environ 13:257-263. https:// doi.org/10.1890/140275

Sei M, Porter AH (2003) Microhabitat-specific early-larval survival of the maritime ringlet (Coenonympha tullia nipisiquit). Anim Conserv 6:55-61. https://doi.org/10.1017/S1367943003003081

Slade NA, Blair SM (2000) An empirical test of using counts of individuals captured as indices of population size. J Mammal 81:1035-1045. https://doi.org/10.1644/1545-1542(2000)081\% 3c1035:AETOUC\%3e2.0.CO;2

Smith WP, Nichols JV (2003) Demography of the Prince of Wales flying squirrel, an endemic of southeastern Alaska temperate rain forest. J Mammal 84:1044-1058. https://doi.org/10.1644/BBa-033

Starrfelt J, Kokko H (2012) Bet-hedging a triple trade-off between means, variances and correlations. Biol Rev 87:742-755. https:// doi.org/10.1111/j.1469-185X.2012.00225.X 
Stearns SC (1992) The evolution of life histories. Oxford University Press, Oxford

Sugianto NA, Newman C, Macdonald DW, Buesching CD (2019) Heterochrony of puberty in the European badger (Meles meles) can be explained by growth rate and group-size: evidence for two endocrinological phenotypes. PLoS One 14:e0203910. https://doi. org/10.1371/journal.pone.0203910

Sugianto NA, Newman C, Macdonald DW, Buesching CD (2020) Reproductive and somatic senescence in the European badger (Meles meles): evidence from lifetime sex-steroid profiles. Zoology 141:125803. https://doi.org/10.1016/j.zool.2020.125803

Sugianto NA, Heistermann M, Newman C, Macdonald DW, Buesching CD (2021) Alternative reproductive strategies provide a flexible mechanism for assuring mating success in the European badgers (Meles meles): an investigation from hormonal measures. Gen Comp Endocrinol 310:113823. https://doi.org/10.1016/j.ygcen. 2021.113823

Sun Q, Stevens C, Newman C, Buesching CD, Macdonald DW (2015) Cumulative experience, age-class, sex and season affect the behavioural responses of European badgers (Meles meles) to handling and sedation. Anim Welf 24:373-385. https://doi.org/10.7120/ 09627286.24.4.373

Tuyttens F (2000) The closed-subpopulation method and estimation of population size from mark-recapture and ancillary data. Can J Zool 78:320-326. https://doi.org/10.1139/z99-218

van den Hoven M, Reilly B (2012) Estimating population size of saddle-billed storks Ephippiorhynchus senegalensis in southern Kruger National Park, South Africa. Ostrich 83:153-159. https:// doi.org/10.2989/00306525.2012.738254

van Lieshout SHJ, Badás EP, Bright Ross JG, Bretman A, Newman C, Buesching CD, Burke T, Macdonald DW, Dugdale HL (2021)
Early-life seasonal, weather and social effects on telomere length in a wild mammal. Mol Ecol. https://doi.org/10.1111/mec.16014

Viallefont A, Kanyamibwa S, Asselain B (1999) Are survival estimates and models obtained by capture-recapture correct? A triple analysis of data with known dates of death. Bird Study 46(suppl):S253S260. https://doi.org/10.1080/00063659909477252

Vicente J, Delahay RJ, Walker NJ, Cheeseman CL (2007) Social organization and movement influence the incidence of bovine tuberculosis in an undisturbed high-density badger Meles meles population. J Anim Ecol 76:348-360. https://doi.org/10.1111/j. 1365-2656.2006.01199.x

White GC (2005) Correcting wildlife counts using detection probabilities. Wildl Res 32:211-216. https://doi.org/10.1071/WR03123

White GC, Burnham KP (1999) Program MARK: survival estimation from populations of marked animals. Bird Study 46(Supplem):120-138. https://doi.org/10.1080/00063659909477239

Wood SN (2011) Fast stable restricted maximum likelihood and marginal likelihood estimation of semiparametric generalized linear models. J R Stat Soc Ser B (statistical Methodol) 73:3-36. https:// doi.org/10.1111/j.1467-9868.2010.00749.x

Woodroffe R, Macdonald DW (1995) Female/female competition in European badgers Meles meles: effects on breeding success. J Anim Ecol 64:12-20. https://doi.org/10.2307/5823

Wright J, Bolstad GH, Araya-Ajoy YG, Dingemanse NJ (2019) Lifehistory evolution under fluctuating density-dependent selection and the adaptive alignment of pace-of-life syndromes. Biol Rev 94:230-247. https://doi.org/10.1111/brv.12451

Publisher's Note Springer Nature remains neutral with regard to jurisdictional claims in published maps and institutional affiliations. 